\title{
MOTIVAÇÃO NAS ORGANIZAÇÕES
}

A relação entre padrões e objetivos individuais, organizacionais e institu cionais faz parte do centro de atenção nas práticas gerenciais e nos estudos sobre as organizações, a estratégia e a economia. A motivação é tema de destaque nesse particular. 0 estudo da motivação, em linhas gerais, consiste na compreensão do comportamento humano, seu começo, foco, intensidade, desenvolvimento e término, abrangendo suas preferências, valorizações e decisões. As sugestões de E ros E. S. Nogueira, doutorando em Administração de Empresas na FGV-EAESP, procuram oferecer contribuições de natureza metodológica e teórica para se dialogar sobre os modos de investigar a motivação nas organizações.
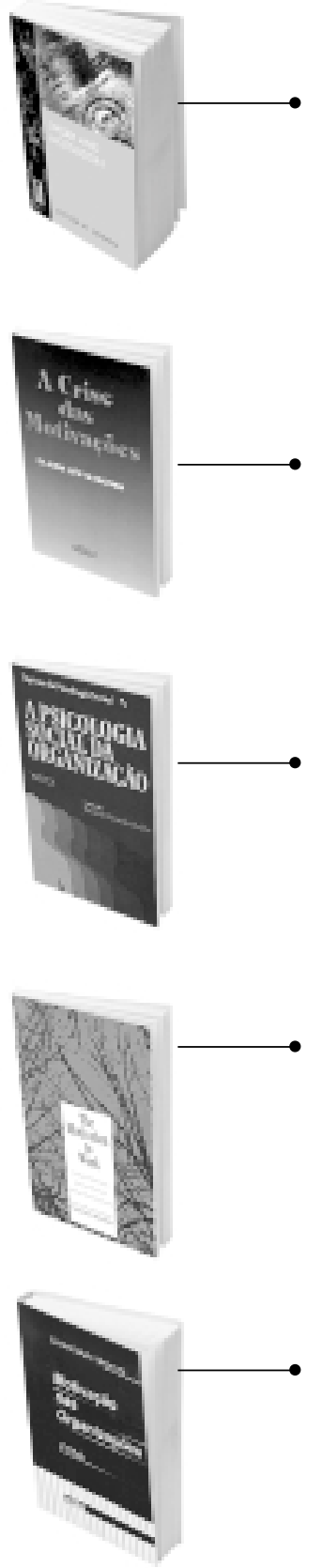

WORK AND MOTIVATION. Victor Harold Vroom. San Francisco: Jossey-Bass Publishers, 1995 [NY: Wiley, 1964]. $395 \mathrm{p}$.

Originalmente publicada em 1964, a obra procura integrar vários modelos para explicar as escoIhas, a satisfação e o desempenho no trabalho e nas organizações. Inclui uma revisão desses modelos, recomendações de caráter metodológico para os estudos e as investigações na área, e a sua proposição denominada teoria da expectância. A teoria afirma que as ações das pessoas sofreriam orientação instrumental: maximizar ganhos e minimizar perdas a partir de escolhas resultantes da valência, instrumentalidade e expectativa concebidas pelo indivíduo em cada situação vivida.

A CRISE DAS MOTIVAÇõES. Claude Lévy-Leboyer. São Paulo: Atlas, 1994, 138 p.

N este ensaio a pesquisadora, nome respeitado mundialmente, faz uma atualíssima apreciação crítica das relações e situações de trabalho, especialmente em face das mudanças da economia e da organização do trabal ho. A perspectiva social que anima sua análise amplia a visão do leitor para abordagens que vão além da ótica psicológica, e sugere indagações inteligentes para os estudos das organizações, da estratégia, da economia e da psicologia do trabalho.

A PSICOLOGIA SOCIAL DAS ORGANIZAÇ̃̃ES. Karl Weick. São Paulo: Edgar Blucher, 1973.120 p.

Esse renomado pesquisador procura esclarecer nesta obra, de forma condensada e el egante, quando e por que as pessoas se organizam. Faz uma proposição teórica que vem servindo de referência aos estudiosos desse tópico e dos correlatos. Sua análise identifica os componentes e processos básicos para conhecer as organizações, assim como para determinar os ambientes em que se inserem.

THE MOTIVATION TO WORK. Frederick Herzberg, Bernard Mausner e Barbara Bloch Surydaman. NY/ London: John Wiley \& Sons Inc./ Chapman \& Hall Limited, 1959.157 p.

A obra disponibiliza os resultados de uma cuidadosa pesquisa sobre a motivação e a atitude no trabalho. Oferece um modelo metodológico com importantes aspectos que podem ser estudados para servir de referência a novas pesquisas nesse campo. Representa um importante passo na direção da objetividade e do atendimento a critérios científicos nas investigações dessa natureza e com esse nível de análise. A obra continua a ser ainda uma proposta teórica de citação constante.

MOTIVAÇÃO NAS ORGANIZAÇõES. Cecília Whitaker Bergamini. São Paulo: Atlas, 1997. 214 p.

A autora apresenta didaticamente uma visão abrangente e as principais idéias e modelos a respeito da motivação. $\mathrm{F}$ az referência aos estudos considerados clássicos, bem como às concepções ditas contemporâneas, e disponibiliza extensa indicação bibliográfica especial izada para o aprofundamento do tema. Adicionalmente, analisa individual e comparativamente as motivações extrínsecas e as intrínsecas, os estilos de conduta e as patologias motivacionais.

NOTA DA REDAÇÃ 0: Os leitores são convidados a visitar a seção "Indicações de Pesquisa" da RAE-eletrônica (www.rae.com.br/eletronica) e conhecer os sites sugeridos pelo autor. 